\title{
Implementation and Evaluation of Certain Properties of a Polymer Matrix Composite Material Reinforced by Fibrous Residues of Saccharum officinarum in View of an Applicability Orientation
}

\author{
Marie Josette Ndengue ${ }^{1,2 *}{ }^{*}$, Merlin Zacharie Ayissi3,4 (), Pierre Marcel Anicet Noah ${ }^{1,2}$ (), \\ Fabien Betene Ebanda1,2 ${ }^{\circ}$, Atangana Ateba ${ }^{1,2}$
}

${ }^{1}$ Department of Mechanical Engineering, ENSET, University of Douala, Douala, Cameroon

${ }^{2}$ Laboratory of Mechanics, University of Douala, Douala, Cameroon

${ }^{3}$ Laboratory of Energy Materials Modelisation and Method, University of Douala, Douala, Cameroon

${ }^{4}$ National Higher Polytechnic School, University of Douala, Douala, Cameroon

Email: *marielongo84@gmail.com

How to cite this paper: Ndengue, M.J., Ayissi, M.Z., Noah, P.M.A., Ebanda, F.B. and Ateba, A. (2021) Implementation and Evaluation of Certain Properties of a Polymer Matrix Composite Material Reinforced by Fibrous Residues of Saccharum officinarum in View of an Applicability Orientation. Journal of Minerals and Materials Characterization and Engineering, 9, 206-225.

https://doi.org/10.4236/jmmce.2021.92015

Received: February 9, 2021

Accepted: March 23, 2021

Published: March 26, 2021

Copyright $\odot 2021$ by author(s) and Scientific Research Publishing Inc. This work is licensed under the Creative Commons Attribution International License (CC BY 4.0).

http://creativecommons.org/licenses/by/4.0/ (c) (i) Open Access

\begin{abstract}
This study examines the implementation and characterization of a polymer matrix composite material reinforced by sugarcane residues. The aim of the study is to enhance the abundantly produced sugarcane bagasse in the form of residues in the processing plants of said sugar cane. The composite material developed takes into account the size parameters and mass load rate of the reinforcement, the variations of which are between $2.5 \mathrm{~mm}$ and $4 \mathrm{~mm}$ respectively for the first parameter and $10 \%$ to $25 \%$ for the second. The load on the test tube during the test has a random orientation. The composite is polyester matrix. The cold compression moulding technique was used in the production of the various samples. Physical properties such as the rate of water absorption and the density of the composite are assessed. The three-point bending tests are carried out with the aim of inducing Young's modulus from the elaborate samples. Analysis of physical properties shows that water absorption increases with the rate of residue load. The average water absorption rate of bagasse fibres is estimated at $8 \%$ for the $2.5 \mathrm{~mm}$ fiber size and $12 \%$ for the $4 \mathrm{~mm}$ fiber size for all composites. Mechanical characterization by bending tests reveals a fragile behavior of the samples tested. Young's modulus decreases when the load rate of fibrous residues increases regardless of the size of the fibers.
\end{abstract}




\section{Keywords}

Composite, Polymer, Bagasse, Young Modulus, Saccharum officinarum

\section{Introduction}

Natural fibre composite materials have many advantages due to their availability, relatively low cost and low density. The mechanical holding of a composite depends not only on the intrinsic properties of its constituents, on the quality of the adhesion between the matrix and the reinforcement, but also on the dispersion of the reinforcement in the matrix [1]. This type of composite has a natural origin and benefits from the many advantages offered by industrial products of organic origin. The incorporation of natural fibres, used as reinforcement in composite materials, is proven to be the use of sisal, flax, jute, hemp, alfa, pineapple, Rhecktophyllum camerunense, coconut sufficiently reported in the literature [2]-[10].

In general, plant fibres represent an attractive alternative to replacing synthetic fibres, such as carbon or glass commonly used as a reinforcement for composite materials [6] [8] [11]. If synthetic fibres have positives, it is the case that natural fibres mark undeniable points from an environmental point. These fibres offer a specific high stiffness and have little environmental impact compared to products derived from synthetic fibers [12]. Natural fibres have a proven track drive in the applied indoor materials and in the automotive industry [13]. Fibre from sugar cane may be associated with these considerations.

The valuation of sugar cane fibres in the field of composite materials may be relevant considering the availability of the raw material. Sugarcane is generally used after processing in industries for the production of alcohol, sugar and biofuels. This industrial transformation of sugar cane generates fibrous residues commonly called bagasse. These industrial residues generally represent about $20 \%-30 \%$, the total mass of the plant [14] [15] [16] [17] [18]. Bagasse production in Cameroon is about 1,008,000 tonnes per year, depending on the production capacity of the two national sugar processing plants located in the cities of Mbandjock and Nkoteng [19]. In Canada, as well as in France, industrial sugarcane residues are generally used for animal feed as a source of energy by combustion on the other hand or as a raw material for the paper industry [15] [19] [20]. Value-added industrial development represents a major ecological and economic challenge in areas with a high predominance of the plant. The implementation of composite materials based on sugar cane bagasse is of real interest to the scientific community. The sugar cane bagasse (Saccharum officinarum) from the residues of the agri-food industry is thus positioned in a logic combining efficiency and sustainability [14].

Several studies have been devoted to polymer composites in which sugarcane bagasse has been incorporated into polymers and polyester to plant fibres [21] [22] [23] [24] [25]. The Postdam et al. [26] study on an epoxy matrix composite 
reinforced by bagasse at load rates $(40 \%$ and $70 \%)$ and different reinforcement sizes $(0.5 \mathrm{~mm}$ and $4 \mathrm{~mm})$ illustrates a bending hold of porous bio-composites that can be likened to a fragile behavior. They also observed that mechanical properties reach their optimum in the case of a high fibre loading rate. Mohamed [27] characterized polyester composite materials reinforced with raw Diss fibers. The results show a density of $1020 \mathrm{~kg} / \mathrm{m}^{3}$ at $20 \%$ and $980 \mathrm{~kg} / \mathrm{m}^{3}$ at $30 \%$ raw fibers demonstrating that density decreases as fibre levels increase. At saturation, the absorption rates of composites at $30 \%$ and $20 \%$ in raw fibers are $9 \%$ and $7 \%$ respectively. An observation is made on the rate of water absorption which increases relatively with the growth of the fiber level. The Young modulus (MOE) found are $20 \%$ and $30 \%$ respectively $2.7 \mathrm{GPa}$ and $3.2 \mathrm{GPa}$. This analysis shows that the MOE increases with the fiber level in the composite thus justifies the positive effect of the presence of fibers as a reinforcement of the composite. Rachchh et al. [28] in their work on treated bagasse fiber composites and a fiberglass-enhanced polyester matrix observed that plate density decreases proportionately with increased bagasse fiber content. The resistance to bending, on the other hand, shows a downward trend inversely proportional to the rate of bagasse fiber. Monteiro et al. [29] investing in untreated coconut fiber reinforced polyester composites show similar results to some authors of the literature, in relation to bending resistance. Cruz et al. [30]'s research on the physical properties of composites provided an analysis of the behaviour of the polyester/Macambabira composite in absorption. The result found shows that water absorption would increase proportionally with the density fraction of the fibers, which corroborates well with different authors of the literature [27] [31] [32].

In terms of literature, plant fibres have intrinsic properties similar to the residues they produce. This is the case with coconut fibers, rice ball fibers [30]. It is with this in mind that fibrous residues of sugar cane called bagasse are studied. These sugarcane residues are very present in Cameroon but very little used in the field of engineering. The sugarcane bagasse produced by the Sugar Company of Cameroon is used as a source of energy in boilers and the rest as fertilizer or abandoned to biodegradability in nature. It is this low-cost availability that justifies the value of the value of the said raw material. The first objective of this study is the implementation of polyester composites reinforced by sugarcane bagasse and secondly the evaluation of intrinsic potentialities such as density, absorption rate. Finally, a study is envisaged to determine the mechanical properties of polyester matrix composites reinforced with residual Saccharum officinarum fibers taking into account the parameters of sample size as well as the rate of test tube loading. This study will open up an additional range in the applicability of composites from tailings in other areas other than those in which they have been used to date.

\section{Experimental Materials and Methods}

\subsection{Materials}

The fibrous residues of the Saccharum officinarum variety recovered from the 
SOSUCAM sugar company in Mbandjock, Cameroon, are composed of a wide variety of short and moist fiber bundles originally. They dried in the open air for two weeks at about $32^{\circ} \mathrm{C}$ in the shade, before being stored in airtight bags for study purposes. The choice of ambient air drying reduces the costs of implementation guaranteed the sustainable aspect of the process [15] [26]. Because of their significant heterogeneity, the fibers were separated into three classes by sifting through a series of sieves with three floors of respective granulometry: 0.5 $\mathrm{mm} ; 2.5 \mathrm{~mm}$ and $4 \mathrm{~mm}$ as shown in Figure 1.

The unsatured polyester (UP) is representative of the matrix used. This is a chemical-mechanical conglomerate of two different products. The first product is a polyacid solution-polyalcool stiffening under the action of the second under duress of an exothermic reaction. The density of the bagasse is $1.25 \mathrm{~g} / \mathrm{cm}^{3}$ and that of the polyester resin obtained is $1.2 \mathrm{~g} / \mathrm{cm}^{3}$ [33] [34]. In this study, fibers are used without prior pre-processing, to allow the determination of properties apart from the effects of chemical agents. The mixture is made in an aluminum container slightly larger than the total volume of the conglomerate. The time allocated to the mixture is a few seconds in order to obtain the most homogeneous materials possible. The mixture is then poured into a rigid metal mould, designed specifically for the occasion and with the following geometric dimensions: $150 \mathrm{~mm} \times 90 \mathrm{~mm} \times 11 \mathrm{~mm}$. The surfaces of the mould are protected by a non-stick coating consisting of fat (butter) with the aim of facilitating removal at the end of the implementation process. The matrix and reinforcement set is cold compressed. The polymerization cycle takes place for one hour. The second phase of implementation was cooling at room temperature. Table 1 presents the samples as well as the test tubes as shown in Figure 2 and Figure 3.

\subsection{Experimental Method}

The purpose of the experiment is the physical characterization of the composite in order to evaluate the water absorption capabilities as well as the density of the samples, which is followed by mechanical characterization in three-point bending in order to determine the mechanical resistance of the material. The deduction of its MOE elasticity module is made. The experimental protocol in Figure 4 served as the basis for this study.

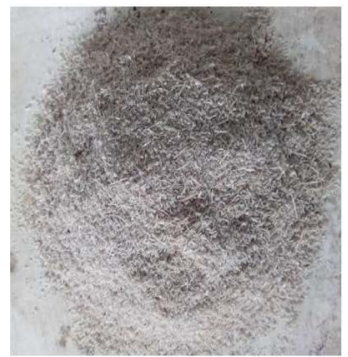

(a)

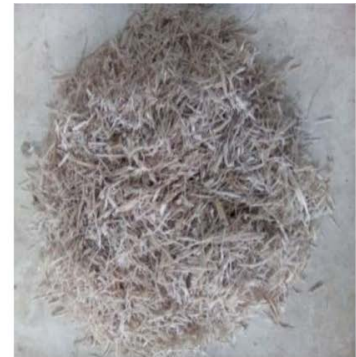

(b)

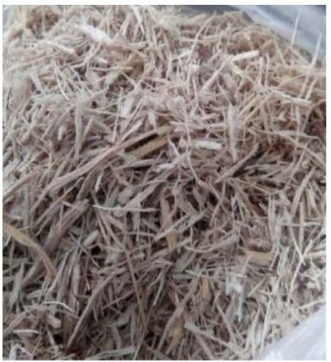

(c)

Figure 1. Bagasse after sieving according to sizes; (a): Size T0 (0 to $0.5 \mathrm{~mm}$ ); (b): Size T1 (0.5 to $2.5 \mathrm{~mm})$; (c): Size T2 $(2.5 \mathrm{~mm}$ to $4 \mathrm{~mm})$. 
Table 1. Nomenclature of samples and specimens.

\begin{tabular}{ccc}
\hline $\mathbf{N}^{\bullet}$ & References & Designations \\
\hline 1 & $10 \%(0.5-2.5 \mathrm{~mm})$ & Sample of $10 \%$ bagasse load, size $2.5 \mathrm{~mm}$ \\
2 & $15 \%(0.5-2.5 \mathrm{~mm})$ & Sample of $15 \%$ bagasse load, size $2.5 \mathrm{~mm}$ \\
3 & $10 \%(2.5-4 \mathrm{~mm})$ & Sample of $10 \%$ bagasse load, size $4 \mathrm{~mm}$ \\
4 & $15 \%(2.5-4 \mathrm{~mm})$ & Sample of $15 \%$ bagasse load, size $4 \mathrm{~mm}$ \\
5 & B11 & Test tube 1 of $10 \%$ bagasse, size $2.5 \mathrm{~mm}$ \\
6 & B21 & Test tube 1 of bagasse at $15 \%$, size $2.5 \mathrm{~mm}$ \\
7 & B31 & Test tube 1 of bagasse at $10 \%$, size $4 \mathrm{~mm}$ \\
8 & B41 & Test tube 1 of bagasse at $15 \%$, size $4 \mathrm{~mm}$ \\
9 & B51 & Test tube 1 of $20 \%$ bagasse, size $4 \mathrm{~mm}$ \\
\hline
\end{tabular}

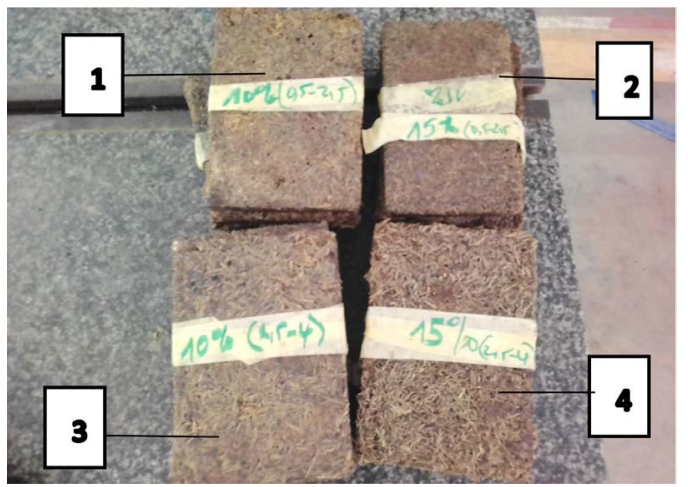

Figure 2. Samples after demoulding.

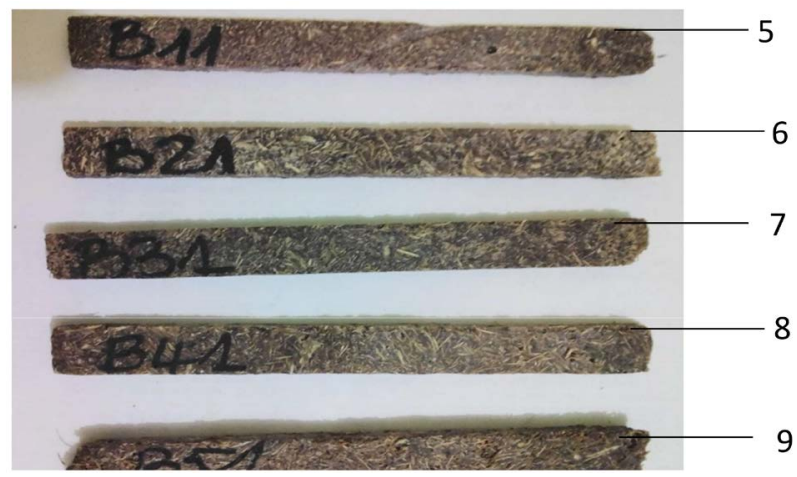

Figure 3. Cut specimens for tests.

\subsubsection{Evaluation of Water Absorption Rate}

Assessing the rate of water absorption is a physical test of the amount of water absorbed during a pre-defined time. The value $(\mathrm{Ta})$ obtained allows us to deduce a characteristic property, including absorption kinetics. Water absorption in this study is carried out on fifteen (15) samples per type of composite material or 75 samples. The so-called samples are dried in a steamer at a temperature of $40^{\circ} \mathrm{C}$ for one hour, as performed by Scida et al. [35]. After passing through the oven, the samples are immediately immersed in distilled water according to the BS EN 


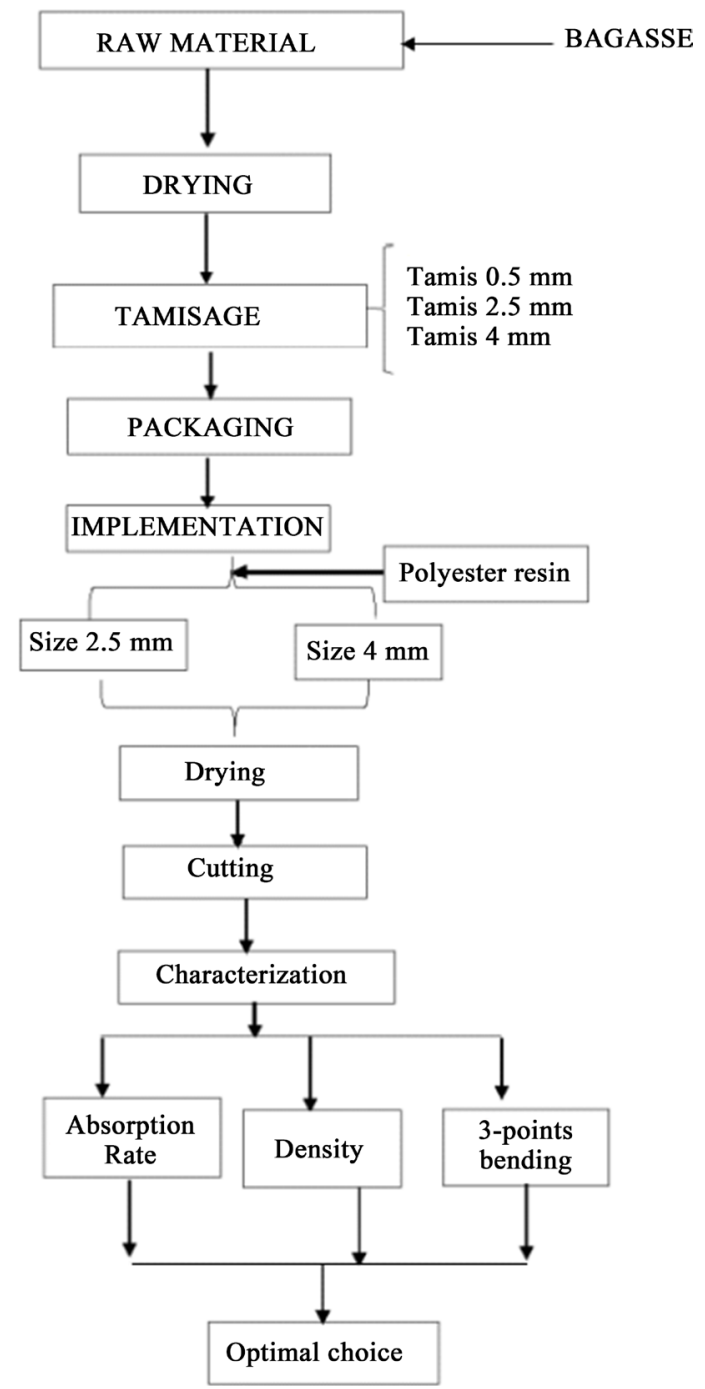

Figure 4. Flowchart of experimental protocol.

ISO 62 [36] standard, then weighed with a $0.01 \mathrm{~g}$ sensitivity scale until the mass saturates and becomes constant. After these different stages, the absorption rate (Ta) in water is estimated from Formula (1):

$$
\mathrm{Ta}=\frac{m_{s}-m_{i}}{m_{i}} \times 100
$$

With $m_{i}$ : Initial sample mass and $m_{s}$ : Sample mass at the moment $\mathrm{t}$ of saturation (in g).

The study of the absorption rate of composites led to the predictive evaluation of composite absorption kinetics studied by the exploitation of two significant models. The study was based on several works, including those of Czel et al., on the one hand, Sikame et al. on the other [37]-[47]. The equations governing the various models successfully implemented are:

Czel et al. model: $M R=a^{*} t^{m}$

Sikame et al. model: $M R=c-a^{*} \exp \left(-k^{*} t\right)-b^{*} \exp \left(-m^{*} t\right)$ 
Table 2. Average values of polyester/bagasse composite model parameters.

\begin{tabular}{cccccccccc}
\hline Models & Samples & $\boldsymbol{A}$ & $\boldsymbol{b}$ & $\boldsymbol{C}$ & $\boldsymbol{k}$ & $\boldsymbol{m}$ & $\boldsymbol{R}^{2}$ & RMSE & SSE \\
\hline & MR10T1 & 0.2382 & & & & 0.1682 & 0.9902 & 0.03217 & 0.01138 \\
& MR10T2 & 0.08003 & & & & 0.2979 & 0.9881 & 0.04123 & 0.0187 \\
Czel & MR15T1 & 0.1062 & & & & 0.2598 & 0.96 & 0.0697 & 0.05343 \\
& MR15T2 & 0.0255 & & & & 0.3392 & 0.9841 & 0.04814 & 0.0255 \\
& MR20T2 & 0.1036 & & & & 0.2643 & 0.9822 & 0.04802 & 0.02537 \\
\hline \multirow{3}{*}{ Sikame } & MR10T1 & 0.5757 & 0.4271 & 1.003 & 0.0007859 & 10.77 & 0.9723 & 0.06348 & 0.03223 \\
& MR15T1 & 0.806 & 0.3312 & 1.137 & 0.0003516 & 0.2217 & 0.9801 & 0.0576 & 0.02654 \\
& MR15T2 & -0.5265 & 1.412 & 1.055 & 0.0005766 & 0.0005602 & 0.9684 & 0.07969 & 0.0508 \\
& MR20T2 & 0.5482 & -25.85 & -25.06 & 0.0009646 & $-1.54 \mathrm{E}-06$ & 0.9166 & 0.1218 & 0.1187 \\
\hline
\end{tabular}

The experimental parameters $(a, t, m, c, k)$ are confined to Table 2 .

\subsubsection{Empirical Deduction of Sample Porosity}

Porosity is the set of voids (pores) in a solid material, these voids are usually filled with fluids (liquid or gas). It is a physical quantity between 0 and $100 \%$, conditioning for a composite material the retention capacities of a substrate. It has an influence on the physical properties of the composite material. The porosity coefficient of the different samples submitted to the study is determined by the Equation (4) [48].

$$
n=\frac{M_{s}-M_{i}}{M_{i}} \times \rho \times 100
$$

With $m_{i}$ : Initial sample mass and $m_{s}$ : Sample mass at the time $t$ of saturation (in g), $\rho$ : density's sample, $n$ : porosity coefficient.

\subsubsection{Density Measurement}

The density of the materials studied is determined by assessing that of each sample by measuring the dimensions of each composite sample using a $1 / 50^{\text {th }}$ sensitivity digital sliding foot, including length $(L)$, width $(I)$ and thickness $(e)$ by direct reading. Then the samples are weighed using a scale with a sensitivity of 0.01 . Weighing the samples is used to determine the mass of samples. The Equation (2) is used to deduce the value of the volume mass of the composite.

$$
\rho_{c}=\frac{m_{c}}{L \times l \times e}
$$

With: composite mass in $(\mathrm{kg}), L$ : length $(\mathrm{m}), 1$ : Width $(\mathrm{m})$, e: thickness $(\mathrm{m})$ and $\left(\mathrm{kg} / \mathrm{m}^{3}\right)$.

\subsubsection{Point Bending Tests}

The need for this test lies in the extent that it can determine the breaking stress (MOR) of the material and deduce the elasticity module (MOE). These experi- 
mental data can predict the applications of such a material. The principle of the test is to measure a displacement crosshead $(y)$ from an effort $(F)$ placed in the middle of two supports [23] [49]. Models from materials science make it possible to make the link between the sizes ( $y$ and $F$ ), the geometry of the piece ( $L, h$ and $b)$ and the characteristics of the material $(\sigma, \varepsilon$ and $E$ ), according to the Equations (6) and (7) [19] [27] [50]:

$$
\begin{gathered}
E=\frac{L^{3} \alpha}{48 I} \\
\sigma_{r u p}=\frac{1.5^{*} F_{r u p}}{b^{*} h^{2}} L
\end{gathered}
$$

With $L$ : distance between supports; $b$ : the width of the test tube; $h$ : the thickness of the test tube; $\alpha$ : slope of the right determined by the path of the force-deformation curve in the elastic field; I: quadratic moment; Frup: force measured at breakage.

To conduct this study, fourteen test tubes $150 \mathrm{~mm}$ long and $7 \mathrm{~mm}$ wide are carried out. The three-point bending tests are carried out on a universal traction and compression test machine with hydraulic jacks with a capacity of $0.946 \times$ $0.233 \mathrm{kN}$ for a $2 \mathrm{~mm} / \mathrm{min}$ cross-crossing speed (ISO 14125). The acronym L represents the distance between the lower supports and is set at $136 \mathrm{~mm}$. The load is applied gradually, at equal distance from the supports and at regular intervals of time, i.e., $2 \mathrm{~mm} / \mathrm{min}$, thanks to the software built into the apparatus until the material breaks, as shown in Figure 5 and Figure 6 .

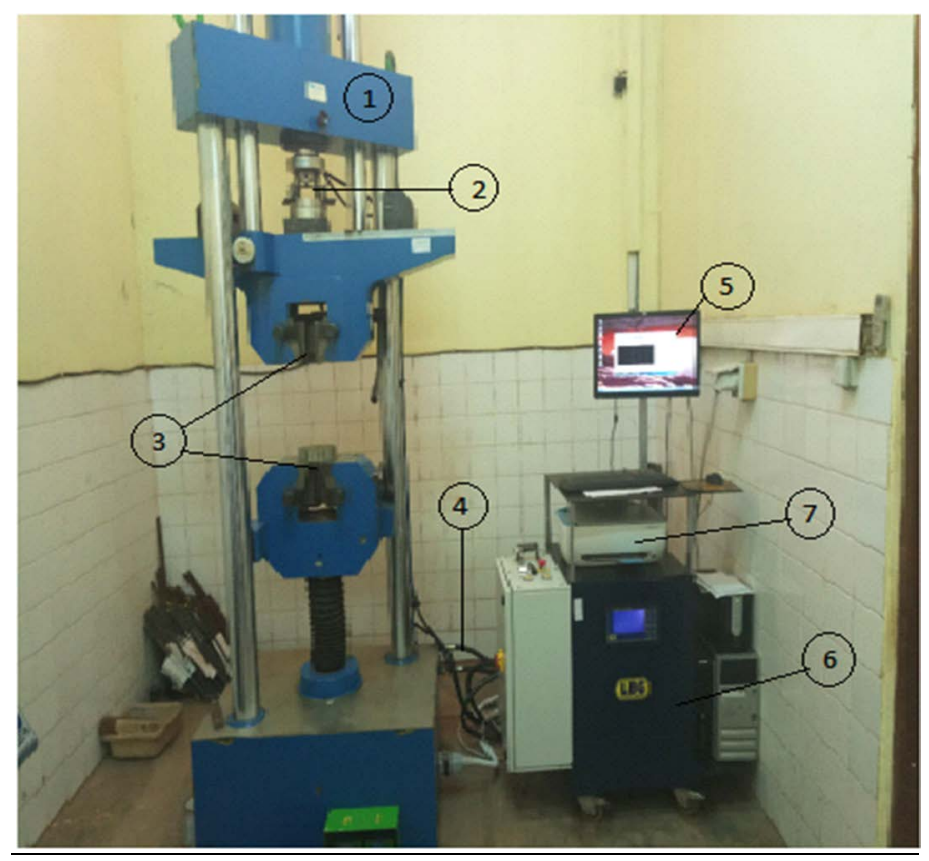

Presentation of the LaboGenie's compression-tension testing device: 1: Universal machine base; 2 : Adapted bending test equipment; 3: Tensile-compression testing equipment; 4: Data cable; 5: Data reading interface; 6: Control unit; 7: Printer.

Figure 5. Tensile-compression testing machine. 


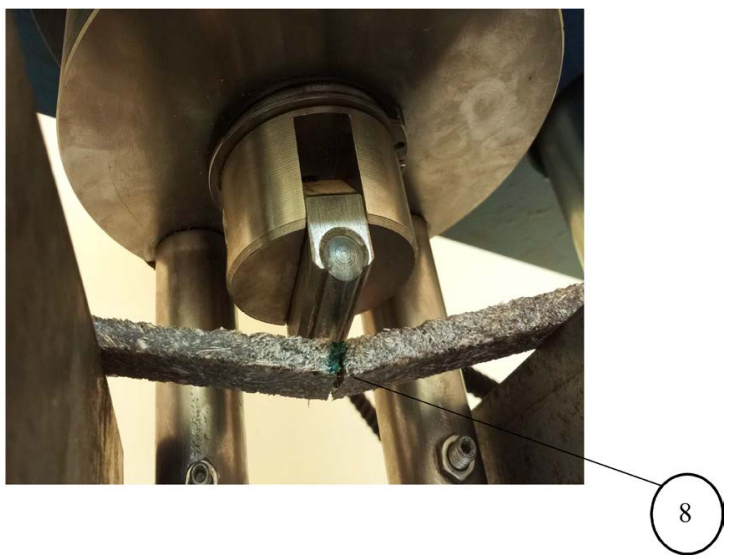

8: Fracture test (bending test).

Figure 6. Compression/tension testing machine (specimen deformed during the threepoint bending test).

\section{Results and Discussions}

At the end of the implementation and the different characterizations, some results were found and analyzed. During the development of the composites, it was observed that some samples had long cross-ulation and did not provide rigid and stable composites, in particular, the $2.5 \mathrm{~mm}$ and $4 \mathrm{~mm}$ composites respectively with load rates of $20 \%$ and $25 \%$.

\subsection{Physical Characterization}

\subsubsection{Water Absorption}

The results of the evaluation of the average absorption rate of composites are represented by the evolutionary curves of the test tubes, shown in Figure 7. With regard to the samples water absorption, the minimum value obtained is $5.736 \%$ which corresponds to that of $\mathrm{Bc} 10 \% \_\mathrm{T} 1$, the maximum water absorption is $24.297 \%$ corresponding to Bc20\%_T2 sample. The average deduced Water absorbtion is approximately $10 \%$. Observation of the experimental values obtained shows that there is a correlation between the rate of water absorption and that of the fiber load in the composite. Indeed, it is observed that the absorption of water from composites increases with the load of fibrous residues. Water absorption is rapid on the first days of immersion for all formulations. This observed behaviour is similar to several studies already conducted [30]. The composites studied are in line with a Fickian-type behavior, with a linear initial curve followed by a saturation plateau, similar to the work carried out by Scida et al. [35]. However, evolutionary curves show that the $20 \%$ composite for the size of 4 $\mathrm{mm}$ has a higher absorption rate, estimated at $24 \%$ compared to the other specimens studied. This observation is explained by the relatively high fibre rate of the sample, the hydrophilic nature of the bagasse and the larger area occupied by the different fibers at the expense of the matrix [51]. The observation made relative to the high absorption of samples with high fiber loads is similar to the results of the work of Sari et al. [52]. 


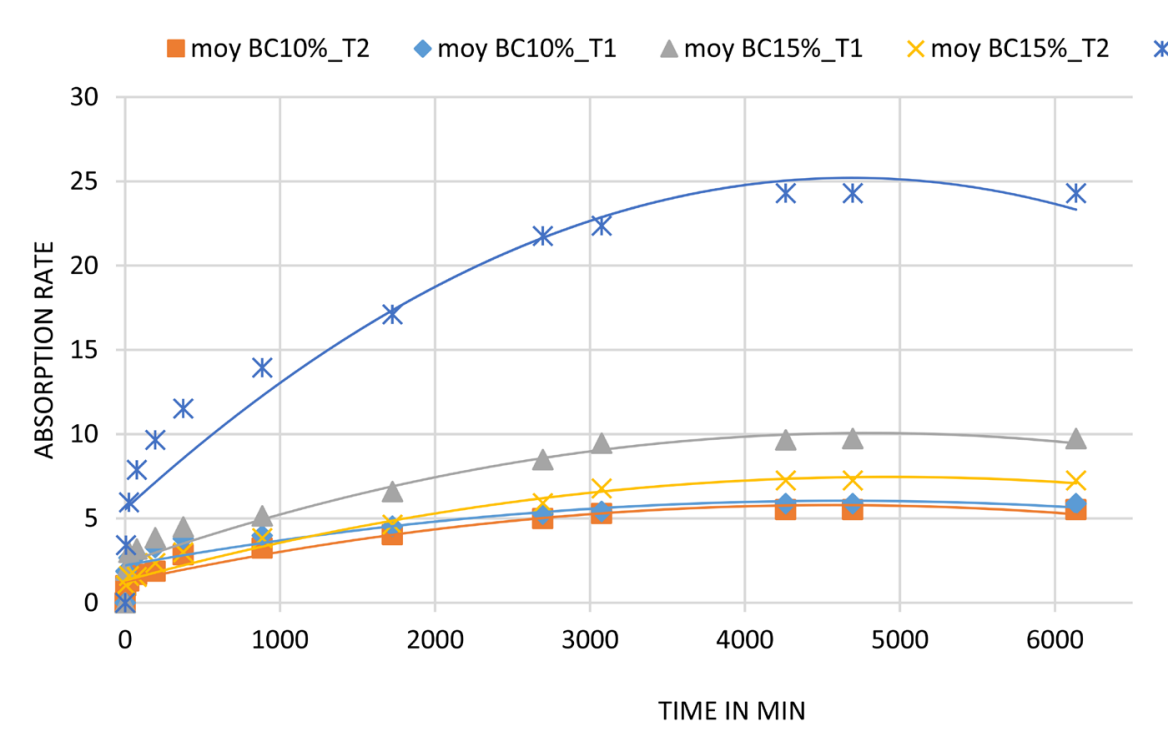

* moy BC20\%_T2

Definitions of samples names

BC10\%_T1: 10\% bagasse fibre content for size $2.5 \mathrm{~mm}$

BC10\%_T2: 10\% bagasse fibre content for size $4 \mathrm{~mm}$ BC15\% T1: 15\% bagasse fibre content for size $2.5 \mathrm{~mm}$

BC15\%_T2: 10\% bagasse fibre content for size $4 \mathrm{~mm}$

BC20\%_T2: 10\% bagasse fibre content for size $4 \mathrm{~mm}$

Figure 7. Evolution of the average values of the absorption rates of the different samples.

The relatively high absorption rate observed inexorably results in a relatively low failure with respect to the inter facial cohesion of the fibers with the matrix. A lower fibre level would ensure better cohesion in the presence of higher humidity relative to loading. However, the high water absorption capacity of the Bc20\%_T2 sample highlights its porous characteristics, probably due to its higher fibre content. This characteristic would be due to the relative intrinsic porosity of the sugarcane fibre. Indeed, this absorption property dependent on a high porosity would therefore prove the existence of a relatively high pore rate in the Bc20\%_T2 composite evaluated at about 17.75\%. Indeed, the studies of Bishweka et al. [48] show that the increase in the water absorption rate is proportional to the increase in the fibre content in the matrix of a sample of biocomposite material. Mohamed [27] places highly porous materials at a matrix fibre content of more than $10 \%$. For this author, above this value, porosity would greatly influence the properties of the material.

In view of the relative porosity of the sample $\mathrm{Bc} 20 \%$ T2, it would be predisposed to a capacity of absorption of acoustic signals. Studies conducted by Gager et al. [53] on non-woven biocomposites subjected to moisture variations establish a link between improved sound absorption properties and increased porosity of the material.

Given the hydrophilic nature of the matrix-strengthening fibers in the composite, the determination of the absorption rate of composites led to a correlation between variation in absorption rate and time. The use of the models from the literature has shown that the composite absorption kinetics of this study are governed by the Sikame and Zel models. These two models better represent the behavior of the relatively studied composite with regard to absorption kinetics. The illustrative results are presented in Figure 8 and Figure 9. 


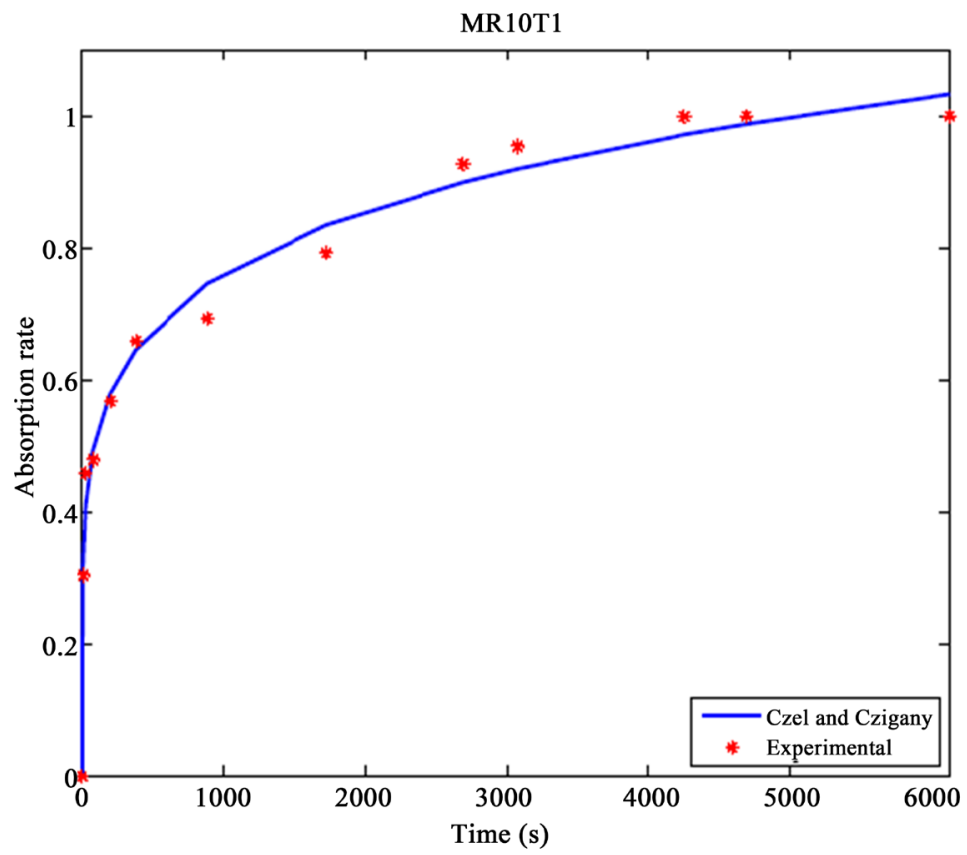

Figure 8. Simulation of the water absorption kinetics of Bc10\%_T1 according to model C. Zel et al.

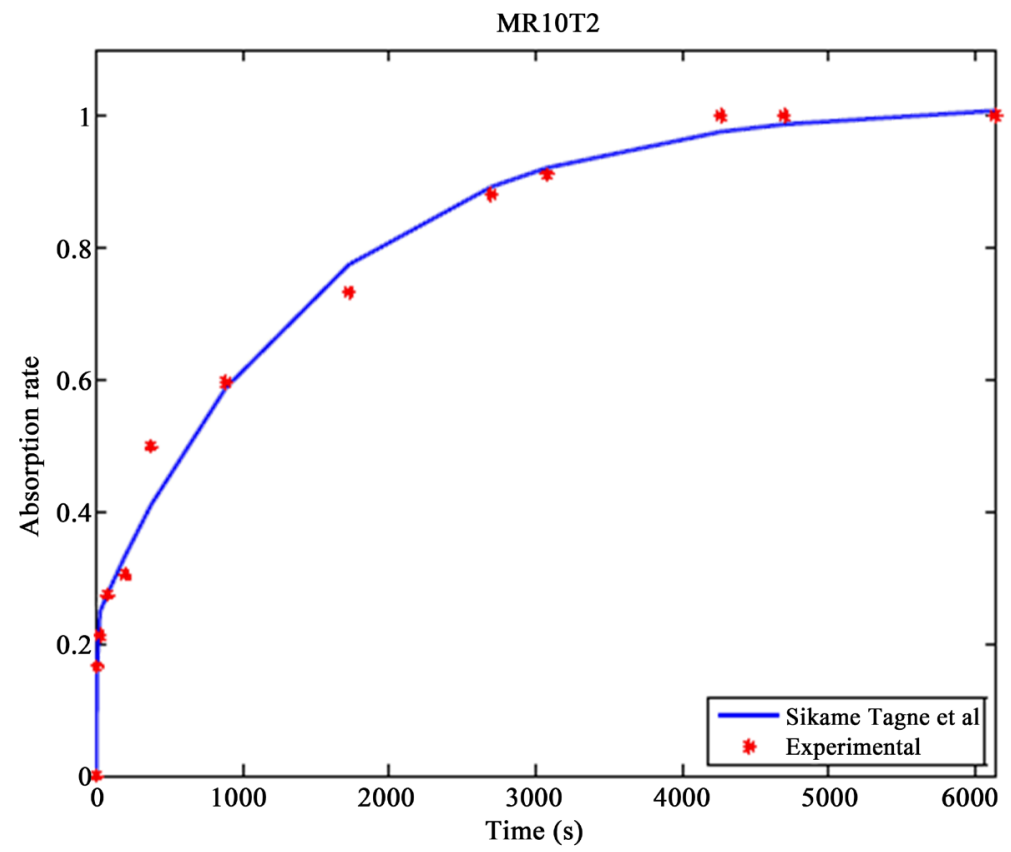

Figure 9. Simulation of the water absorption kinetics of Bc10\%_T1 according to model Sikame et al.

Analysis of Table 2 shows that the Sikame et al. models as well as Czel et al. have a better $\mathrm{R}^{2}$ correlation coefficient respectively for the Bc10\%_T2 and Bc15\%_T1 and Bc15\%_T2, Bc20\%_T2 and Bc10\%_T1.

\subsubsection{Density}

Analysis of the average density shows that the density of all composites decreases 
with the increase in fiber content regardless of size, as shown in Table 3 and Figure 10 . The Bc20\%_T2 composite has a relatively low density of $755.1 \mathrm{~kg} / \mathrm{m}^{3}$ compared to other samples, this predisposition could justify its high absorption rate as well as its low mass. This low density is similar to that of some wood species between $350 \mathrm{~kg} / \mathrm{m}^{3}$ and $1100 \mathrm{~kg} / \mathrm{m}^{3}$ and could replace it in construction areas such as ceiling, false ceiling and others [54].

\subsection{Mechanical Characterization}

The 3-point bending curves of the samples tested are presented in Figure 11. Observation of the curves shows that the movement is proportional to the effort

Table 3. Average values of the apparent densities of the composites.

\begin{tabular}{ccccccc}
\hline COMPOSITES & UP & Bc10\%_T1 & Bc10\%_T2 & Bc15\%_T1 & Bc15\%_T2 & Bc20\%_T2 \\
\hline$\rho_{c}\left(\mathrm{~kg} / \mathrm{m}^{3}\right)$ & 1192,10 & 1022,745 & 1041,087 & 987,223 & 982,876 & 755,133 \\
Ecart-type $\rho_{c}$ & 48,007 & 29,142 & 57,976 & 59,180 & 67,925 & 129,824 \\
\hline
\end{tabular}

UP: Unsaturated polyester.

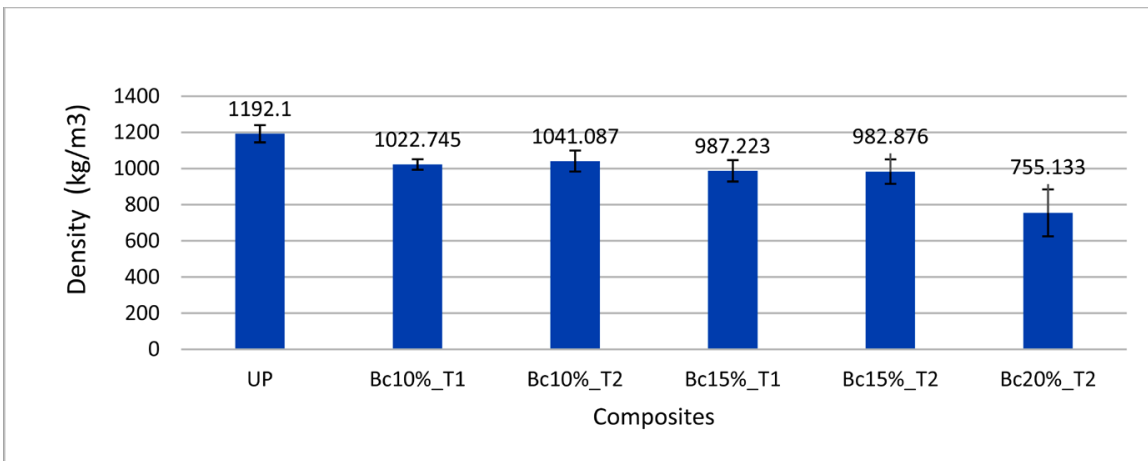

Figure 10. Distribution of the mean density values of the different composites.

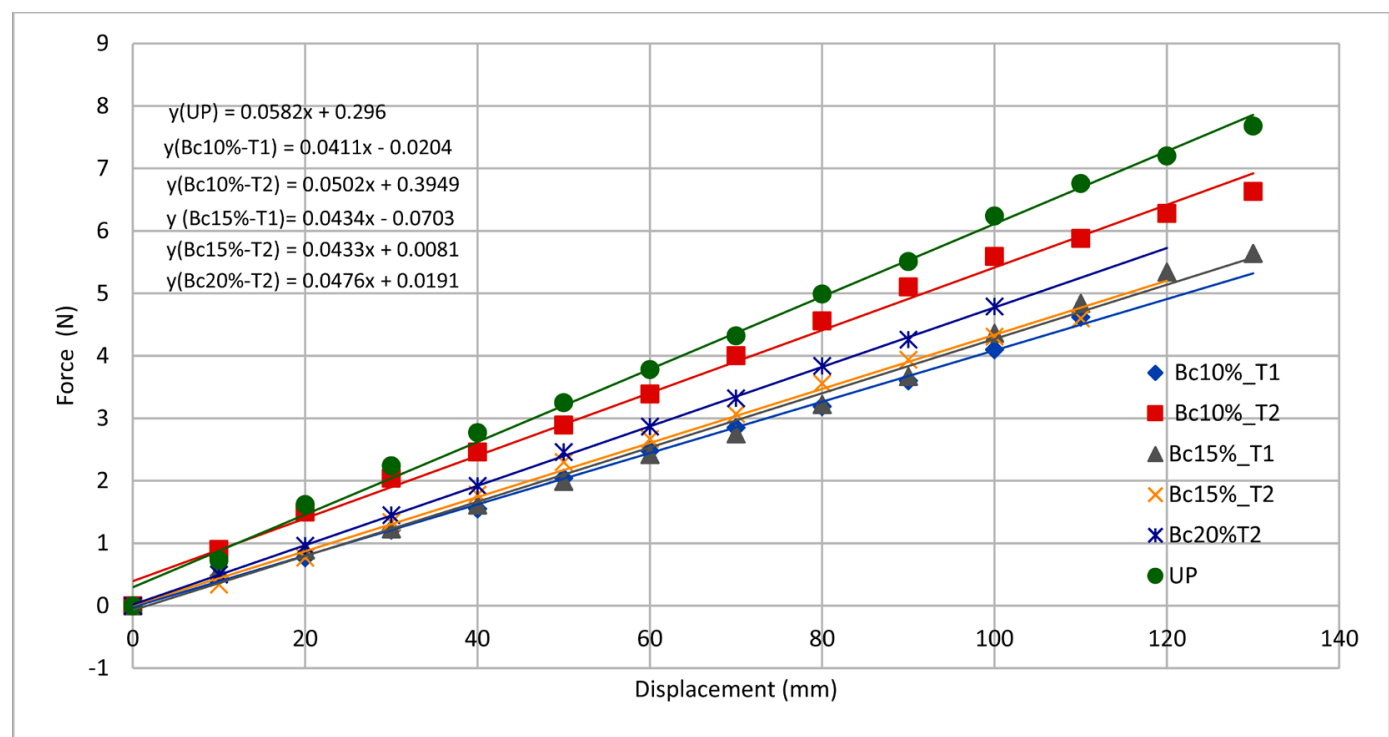

Figure 11. Force-displacement curves of different bagasse/polyester composites. 
exerted on each test tube. The stress grows with the arrow however, the amplitude is higher for samples with small reinforcements of $2.5 \mathrm{~mm}$. This behaviour is observed on the $\mathrm{Bc} 10 \%$ T 1 and $\mathrm{Bc} 15 \%$ _ $\mathrm{T} 1$ composites, reflecting a high fragility of the material compared to $4 \mathrm{~mm}$-long samples. The length of the fiber increases the contact surface with the binder giving the composite a certain stiffness during the test. This property translates into the value of the stress on the composite as shown in Figure 12 after the test. The bending elasticity module of each sample is deduced from the slope of the linear adjustment right of each cloud. The results obtained in Figure 3.8 show that the resistance to bending decreases with the increase in the load rate of the fiber, this is true regardless of the size of the fibers. The average minimum value of bend resistance is 27.13 $\mathrm{MPa}$ for a fiber size of $4 \mathrm{~mm}$ and an average maximum value of $45.57 \mathrm{MPa}$. The minimum and maximum values of bend resistance obtained during the relative test for samples with $2.5 \mathrm{~mm}$ length fibers are: $36.7 \mathrm{MPa}$ and $37.04 \mathrm{MPa}$ respectively. The results in Figure 3.8 show a proportionality coefficient of $0.3 \pm 0.01$.

Figure 13 shows the average elasticity modules (MOE) of composites that decrease as the load rate increases. The finding is made on the Bc10\%_T2 composite which has a Young module about $8 \%$ higher than that of the pure MATRIX

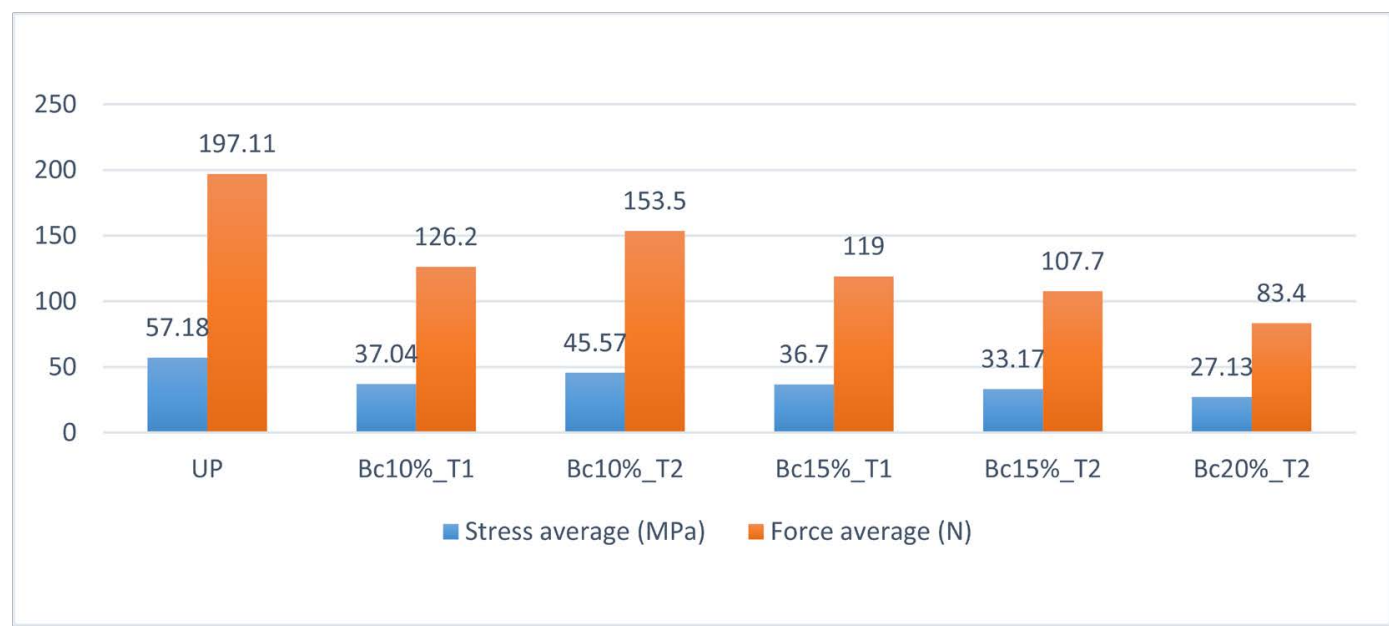

Figure 12. Distribution of the mean values of breaking stresses and breaking forces of the different composites.

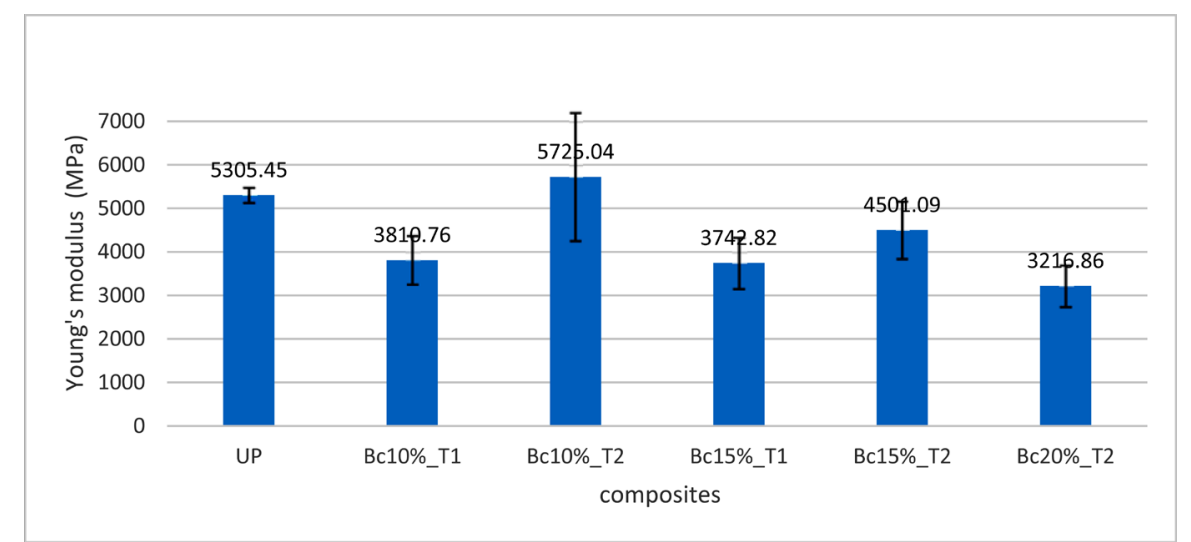

Figure 13. Distribution of mean Young's modulus values of the different composites. 
UP with a value of $5725.04 \mathrm{Mpa}$. In this composite, the bagasse effectively strengthens the matrix, hence this significant result which demonstrates that the correct rigidity of Bc10_T2.

Figure 12 and Figure 13 show the effect of length in fibers on bending resistance and the modules of bagasse/polyester composites. This is similar to that of Al-Kaabi et al. on DPF/polyester composites [55]. The bending resistance of the bagasse/polyester composites in Bc10\% with a size of (2.5 - 4) mm supposedly large, is $45.57 \mathrm{Mpa}$, or about $19 \%$ higher than that of samples of smaller size $(0.5$ - 2.5) $\mathrm{mm}$. Large composites in Bc10\% have an average bending module of $5725.04 \mathrm{MPa}$, which is about $51 \%$ higher than smaller fiber samples.

These results highlight the Bc10\%_T2 composite whose physical and mechanical characteristics are superior to those of the other composites studied. The results of the experimental study show that the Bc10\%_T2 sample has relatively better physical and mechanical properties than the other samples studied. this sample has a relatively low water absorption rate evaluated at $6 \%$ and a higher density. Its Young's modulus is on the one hand $8 \%$ higher than that of the matrix and on the other hand, this modulus is higher than that of the other samples studied. These characteristics of Bc10\%_T2 are a singularity related to the study in relation to the Hall petch law. The mechanical properties of the bagasse/polyester composites studied are all as interesting as those of some composites encounters in the literature, under the same conditions of implementation, at different sizes and at different reinforcement rates, the work of such as the work of Jayabal et al. and S.N. Monteiro et al., whose results in the mechanical properties of polyester/coconut composites show that the polyester/bagasse composites studied can replace low-load automotive components because they have a low cost of implementation and are biodegradable [5] [28]. Young's modulus of the composites studied is superior to the wood composite panels, which could guide its application as false ceilings in civil engineering or sustainable mobility systems [56].

\section{Conclusion}

The purpose of this study was to implement and evaluate certain properties of a polymer matrix composite material reinforced by fibrous residues of Saccharum officinarum. Polyester matrix composite materials reinforced with sugarcane bagasse have been developed and characterized physically and mechanically. The results of the physical characterization show that the rate of water absorption of the test tubes is high when the fiber content increases. The very high absorption of the composite at $20 \%$ compared to other composites, can predispose it to good acoustic properties that it would be interesting to determine by specific tests. The increase in the fibre level in the test tubes appears to decrease the density of the material. Mechanical characterization, including the composite bending study, revealed that bending resistance (MOR) decreases as fiber levels increase. This seems to be true regardless of the size of the fibers. As for the elas- 
ticity module (MOE) of composites, it decreases when the load rate increases. However, the Bc10\%_T2 composite has a Young modulus that is $8 \%$ higher than the matrix. An observation on this sample, shows that it has higher properties than the other specimens studied. The characteristics of the composites are certainly not very reinforcing for the matrix given the specific properties of the polyester determined in this study. However, the determined properties allow us to position ourselves in the wake of the composites of the literature and to add to them less structural application areas. Composites with a fiber content greater than $20 \%$ appear to be unusable in terms of their physical appearance. Indeed, it has been found that for fibre contents above $20 \%$ and $25 \%$ respectively for fibre sizes T1 $(2.5 \mathrm{~mm})$ and T2 $(4 \mathrm{~mm})$, the samples show an irregular physical appearance (bubbles and large pores). The sufficiently advanced state of anisotropy of the samples considered does not allow a relative exploitation. The fibre contents evaluated at $20 \%$ and $25 \%$ respectively for the T1 $(2.5 \mathrm{~mm})$ and $\mathrm{T} 2(4 \mathrm{~mm})$ fibre sizes are practical thresholds allowing an exploitation within the framework of this study. Another moulding process could promote a good intake of composite components. In order to have more areas of application, the determination of thermal characteristics could emerge from the eco-insulating properties of these composites. Similarly chemical treatments on sugarcane bagasse would be interesting to observe. However, to reduce the environmental impact due to the use of heat-efficient matrixes, such as polyester, the orientation towards natural matrixes such as polylactic acid, tannin or natural rubber, reinforced by natural fibres could be interesting from an ecological point of view.

\section{Acknowledgements}

The authors thank the Yaounde LabGenie and the Mechanical Laboratory of the ENSET in Douala for the right granted to the various tests.

\section{Conflicts of Interest}

The authors declare no conflicts of interest regarding the publication of this paper.

\section{References}

[1] Layth, M., Ansari, M.N.M., Pua, G., Mohammad, J. and Saiful, M.I. (2015) A Review on Natural Fiber Reinforced Polymer Composite and Its Applications. International Journal of Polymer Science, 2015, Article ID: 243947. https://doi.org/10.1155/2015/243947

[2] Saaidia, A., Bezazi, A. and Scarpa, F. (2015) Caractérisation des bio-composites Jute/polyester par l'utilisation de la méthode Statistique de Weibull et l'analyse de variance ANOVA. 22ème Congrès Français de Mécanique, Lyon, 24-28 August 2015, AFM 2491-715X. http://hdl.handle.net/2042/57504

[3] Anindya, D., Sumitesh, D., Ashok, M. and Rokesh, L. (2017) A Study on the Mechanical Behaviors of Jute-Polyester Composites. Procedia Engineering, 173, 631-638. https://doi.org/10.1016/j.proeng.2016.12.120 
[4] Ndoumou, B., Legrand, R., Meva'a, L., Ouagne, P., Betene Ebanda, F., Noah, P.M. and Ateba, A.J. (2020) Physico-Chemical and Thermal Characterization of a Lignocellulosic Fiber, Extracted from the Bast of Cola Lepidota Stem. Journal of Minerals and Materials Characterization and Engineering, 8, 377-392. https://doi.org/10.4236/jmmce.2020.85024

[5] Jayabal, S. and Natarajan, U. (2011) Influence of Fiber Parameters of Tensile, Flexural and Impact Properties of Nonwoven Coir-Polyester Composite. The International Journal of Advanced Manufacturing Technology, 54, 639-648. https://doi.org/10.1007/s00170-010-2969-8

[6] Ze, E.P., Noah, P.M., Nnomo, E.D., Wiryikfu, N.C., Fabien, B.E., Ngahiyi, A.C.V. and Ateba, A. (2020) Elaboration and Characterization of Composite Material Reinforced by Papaya Trunk Fibers (Carica papaya) and Particules of the Hulls of the Kernels of the Winged Fruits (Canaruim schweinfurthii) with Polyester Matrix. Journal of Minerals and Materials Characterization and Engineering, 8, 341-352. https://doi.org/10.4236/jmmce.2020.85021

[7] Betene Omgba, A.D., Ebanda Betene, F., Martoïa, F., Dumont, P.J.J., Ateba, A. and Noah, P.M.A. (2020) Physico-Chemical and Thermal Characterization of Some Lignocellulosic Fibres: Ananas comosus (AS), Neuropeltis acuminatas (NA) and Rhecktophyllum camerunense (RC). Journal of Minerals and Materials Characterization and Engineering, 8, 205-222. https://doi.org/10.4236/jmmce.2020.84014

[8] Noah, P.M.A., Betene Ebanda, F., Obame, S.V., Beassoum, A., Bindjeme, M.C. and Ateba, A. (2020) Elaboration and Characterization of a Hybrid Composite Material with Two Particles of the Same Size: Coco Shells and Palm Shells. Open Journal of Composite Materials, 10, 77-91. https://doi.org/10.4236/ojcm.2020.104006

[9] Mechakra, H., Nour, A., Lecheb, S. and Chellil, A. (2015) Mechanical Characterizations of Composite Material with Short Alfa Fibers Reinforcement. Composite Structures, 124, 152-162. https://doi.org/10.1016/j.compstruct.2015.01.010

[10] Mewoli, A.E., Segovia, C., Betene Ebanda, F., Noah, P.M.A., Ndiwe, B. and Njom, A.E. (2020) Physical-Chemical and Mechanical Characterization of the Bast Fibers of Truimfetta cordifolia A. Rich. from Equatorial Region of Cameroon. Journal of Minerals and Materials Characterization and Engineering, 8, 163-176. https://doi.org/10.4236/jmmce.2020.84011

[11] Betene Ebanda, F. (2012) Etude des propriétés mécaniques et thermiques du plâtre renforcé de fibres végétales tropicales. Thèse, Université Blaise Pascal Clermont-Ferrand II. French.

[12] Betene Ebanda, F., Noutegomo, B. and Ateba, A. (2018) Study of the Diffusion Behavior of Water Vapor Sorption in Natural Fiber: Rhecktophyllum camerunense. Indian Journal of Engineering, 15, 143-150.

[13] Andrieu, A., Hedou, M., Mouren, A. and Pham, P. (2019) Les biocomposites thermodurcissables à base de lin dans l'automobile. Rapport de veille technologique et d'intelligence économique, Grenoble INP-PAGORA.

[14] Mussig, J. (2010) Industrial Applications of Natural Fibres. Structure, Properties and Technical Applications. John Wiley \& Sons, Ltd., Amsterdam. https://doi.org/10.1002/9780470660324

[15] Michel, D. (2013) Evaluation du potentiel fibreux et textile de la canne à sucre a sucre Saccharum officinarum. Thèse, Universite de Haute Alsace Mulhouse.

[16] Meirhaeghe, C. (2011) Evaluation de la disponibilité et de l'accessibilité de fibres végétales à usages matériaux en France. Fibres recherche développement ${ }^{\oplus}$, ADEME.

[17] Chiparus, O.I. (2004) Bagasse Fibre for Production of Nonwoven Material. Thèse de 
doctorat: Ecologie humaine, Université de Louisiane et Roumanie.

[18] Balaji, A., Karthikeyan, B. and Sundar Raj, C. (2015) Bagasse Fiber-The Future Biocomposite Material: A Review. International Journal of ChemTech Research, 7, 223-233.

[19] Rapport Developpement Durable Afrique (2017) SOMDIAA.

[20] Diogo, A. and Silva, L. (2012) LCA Application: The Case of the Sugar Cane Bagasse Electricity Generation in Brazil. In: Dornfeld, D.A. and Linke, B.S., Eds., Leveraging Technology for a Sustainable World, Springer, Berlin, 85-90.

https://doi.org/10.1007/978-3-642-29069-5_15

[21] Brugnago, R.J., Gundappa Satyanarayana, K., Wypych, F. and Pereira Ramos, L. (2011) Effect of Steam Explosion on the Production of Sugarcane Bagasse/Polyester Composites. Composites Part A, 42, 364-370. https://doi.org/10.1016/j.compositesa.2010.12.009

[22] Scarpini Candido, V., Rios da Silva, Q.C., Tonini Simonassi, N., Santos da Luz, F. and Monteiro, S.N. (2017) Toughness of Polyester Matrix Composites Reinforced with Sugarcane Bagasse Fibers Evaluated by Charpy Impact Tests. Journal of Materials Research and Technology, 6, 334-338. https://doi.org/10.1016/j.jmrt.2017.06.001

[23] Onésippe, C., Passe-Coutrin, N., Toro, F., Delvasto, S., Bilba, K. and Marie-Ange, A. (2010) Sugar Cane Bagasse Fibres Reinforced Cement Composites: Thermal Considerations. Compostie, Part A: Applied Science and Manufacturing, 41, 549-556. https://doi.org/10.1016/j.compositesa.2010.01.002

[24] Vilay, V., Mariatti, M., Mat Taib, R. and Mitsugu, T. (2008) Effect of Fiber Surface Treatment and Fiber Loading on the Properties of Bagasse-Fiber Reinforced Unsaturated Polyester Composites. Composites Science and Technology, 68, 631-638. https://doi.org/10.1016/j.compscitech.2007.10.005

[25] Bezerra Sandes, A.L.M., Raissa de Almeida, G., Picanço, M.O., Scarpini Cândido, V. and Monteiro, S.N. (2014) Characterization of Epoxy Matrix Composites Incorporated with Sugarcane Bagasse Fibers. Materials Science Forum, 775-776, 102-106. https://doi.org/10.4028/www.scientific.net/MSF.775-776.102

[26] Postdam, G., Birame Gning, P., Piezel, B., Geslain, A. and Fontaine, S. (2017) Development of a Composite Material Made from Sugar Cane Fiber. Ecole des ponts ParisTech, 28-30 Juin. https://hal.archives-ouvertes.fr/hal-01621626

[27] El Hadi Bourahli, M. (2014) Caractérisation des composites verre, jute et Diss/polyester. Thèse, Université FERHAT ABBAS-SETIF 1.

[28] Rachchh, N.V. and Trivedi, D.N. (2018) Mechanical Characterization and Vibration Analysis of Hybrid E-Glass/Bagasse Fiber Polyester Composites. Procedia Materials Today: Proceedings, 5, 7692-7700. https://doi.org/10.1016/j.matpr.2017.11.445

[29] Monteiro, S.N., Terrones, L.A.H. and D’Almeida, J.R.M. (2008) Mechanical Performance of Coir Fiber/Polyester Composites. Polymer Testing, 27, 591-595. https://doi.org/10.1016/j.polymertesting.2008.03.003

[30] Cruz, V.C., Nóbrega, M.M. and Cavalcanti, W.S. (2010) Water Absorption in Macambira/Unsaturated Polyester Composites: An Experimental Study. VI Congresso Nacional de Engenharia Mecânica CONEM2010, Brasil, 1-5.

[31] Bezerra, A.F.C., Cavalcanti, W.S., Barbosa de Lima, A.G., de Souza, M.J. and Nascimento, P.T.R. (2017) Unsaturated Polyester Composite Reinforced with Caroá Fiber (Neoglaziovia variegata): Water Sorption and Mechanical Properties. Revista Matéria, 22, e-11842. https://doi.org/10.1590/s1517-707620170002.0175

[32] Dhakal, H.N., Zhang, Z.Y. and Richardson, M.O.W. (2007) Effect of Water Absorp- 
tion on the Mechanical Properties of Hemp Fibre Reinforced Unsaturated Polyester Composites. Composites Science Technology, 67, 1674-1683. https://doi.org/10.1016/j.compscitech.2006.06.019

[33] Saab, H. (2013) Développement de bio-composites à base de fibres végétales et de colle écologique. Thèse du 19 décembre.

[34] Elanchezhian, C., Vijaya, B.R., Ramakrishnan, G., Rajendrakumar, M., Naveenkumar, V. and Saravanakumar, M.K. (2018) Review on Mechanical Properties of Natural Fiber Composites. Materials Today: Proceedings, 5, 1785-1790.

https://doi.org/10.1016/j.matpr.2017.11.276

[35] Scida, D., Assarar, M., Rezak, A. and Poilâne, C. (2011) Effect of Humidity on Mechanical Properties of Flax Fibres Reinforced Composites.

https://hal.archives-ouvertes.fr/hal-00597760

[36] European Standard EN ISO 62 (1999) Plastics-Determination of Water Absorption, BS EN ISO 1999, 62, 1-8.

[37] Mbou, E.T., Njeugna, E., Kemajou, A., Tagne Sikame, N.R. and Ndapeu, D. (2017) Modelling of the Water Absorption Kinetics and Determination of the Water Diffusion Coefficient in the Pith of Raphia vinifera of Bandjoun, Cameroon. Advances in Materials Science and Engineering, 2017, Article ID: 1953087.

https://doi.org/10.1155/2017/1953087

[38] Pilosof, A.M.R., Boquet, R. and Batholomai, G.B. (1987) Kinetics of Water Uptake to Food Powders. Journal of Food Science, 50, 1538-1541.

https://doi.org/10.1111/j.1365-2621.1985.tb13334.x

[39] Mohsenin, N.M. (1986) Physical Properties of Plant and Animal Material. 2nd Edition, Gordon and Breach Science Publishers, New York.

[40] Singh, B.P.N. and Kulshrestha, S.P. (1987) Kinetics of Water Sorption by Soybean and Pigeonpea Grains. Journal of Food Science, 52, 1538-1541.

https://doi.org/10.1111/j.1365-2621.1987.tb05874.x

[41] Peleg, M. (1988) An Empirical Model for the Description of Moisture Sorption Curve. Journal of Food Science, 53, 1216-1217. https://doi.org/10.1111/j.1365-2621.1988.tb13565.x

[42] Garcia-Pascual, P., Sanjuan, N., Melis, R. and Mule, A. (2006) Morchella esculenta (Morel) Rehydration Process Modelling. Journal of Food Engineering, 72, 346-353. https://doi.org/10.1016/j.jfoodeng.2004.12.014

[43] Gowen, A., Abu-Ghannam, N., Frias, J. and Oliveira, J. (2007) Modelling the Water Absorption Process in Chickpeas (Cicer arietinum L.) the Effect of Blanching Pre-Treatment on Water Intake and Texture Kinetics. Journal of Food Engineering, 78, 810-819. https://doi.org/10.1016/j.jfoodeng.2005.11.022

[44] Czel, G. and Czigany, T. (2008) A Study of Water Absorption and Mechanical Properties of Glass Fiber/Polyester Composite Pipes-Effects of Specimen Geometry and Preparation. Journal of Composite Materials, 42, 2815-2827. https://doi.org/10.1177/0021998308096668

[45] Vega-Galvez, A., Notte-Cuello, E., Lemus-Mondaca, R., Zura, L. and Miranda, M. (2009) Mathematical Modelling of Mass Transfer during Rehydration Process of Aloe vera (Aloe barbadensis Miller). Food and Bioproducts Processing, 87, 254-260. https://doi.org/10.1016/j.fbp.2008.10.004

[46] Gornicki, K., Kaleta, A., Winiczenko, R., Chojnacka, A. and Janaszek, M. (2013) Evaluation of Drying Models of Apple (Var Ligol) Dried in a Fluidized Bed Dryer. Energy Conversion and Management, 67, 179-185. https://dx.doi.org/10.1016/j.enconman.2012.11.011 
[47] Sikame Tagne, N.R., Njeugna, E., Fogue, M., Drean, J.-Y., Nzeukou, A. and Fokwa, D. (2014) Study of Water Absorption in Raphia vinifera Fibres from Bandjoun, Cameroon. The Scientific World Journal, 2014, Article ID: 912380. https://doi.org/10.1155/2014/912380

[48] Bishweka Biryondeke, C., Ngapgue, F. and Olembe Musangi, G. (2016) Study of Water Absorption Coefficient of Goma's Volcanic Aggregates and Its Influence in Formulating Concrete. International Journal of Innovation and Applied Studies, 15, 141-152. http://www.ijias.issr-journals.org

[49] Abd Halip, J., Lee Seng, H., Zaidon, A., Md Tahir, P., Lum Wei, C. and Mohd Khairun, A.U. (2019) Effect of Treatment on Water Absorption Behavior of Natural Fiber-Reinforced Polymer Composites. In: Jawaid, M., Thariq, M. and Saba, N., Eds., Mechanical and Physical Testing of Biocomposites, Fibre-Reinforced Composites and Hybrid Composites, Elsevier Ltd., Amsterdam, 141-156.

https://doi.org/10.1016/B978-0-08-102292-4.00008-4

[50] Rouam, K. (2014) Elaboration, caractérisation mécanique et hygrothermique d'un stratifié renforcé par des fibres naturelles. Université m'hamed bougara-boumerdes, Algérie.

[51] Omid, N., Debnath, S., Kai Beh, J. and Yeakub, A.M. (2018) Mechanical Performance and Moisture Absorption of Unidirectional Bamboo Fiber Polyester Composite. Materials Science Forum, 911, 88-94.

https://doi.org/10.4028/www.scientific.net/MSF.911.88

[52] Sari, N.H. and Suteja, S. (2020) Corn Husk Fibers Reinforced Polyester Composites: Tensile Strength Properties, Water Absorption Behavior, and Morphology. IOP Conference Series: Materials Science and Engineering, 722, Article ID: 012035. https://doi.org/10.1088/1757-899X/722/1/012035

[53] Gager, V., Le Duigou, A., Bourmaud, A., Pierre, F., Behlouli, K. and Baley, C. (2019) Hydro-Mechanical Behaviour of Non-Woven Biocomposites with Moisture Variations. Comptes rendus des JCN 21-Bordeaux INP-1-3 juillet 2019.

[54] Djoudi, T., Hecini, M., Scida, D., Djebloun, Y. and Guerira, B. (2018) Caractérisation physique et mécanique du bois et des fibres issus d'une palme mûre de palmier dattier. Matériaux \& Techniques, 106, 403. https://doi.org/10.1051/mattech/2018056

[55] Al-Kaabi, K., Al-Khanbashi, A. and Hammami, A. (2005) Date Palm Fibers as Polymeric Matrix Reinforcement: DPF/Polyester Composite Properties. Polymer Composites, 26, 486-497. https://doi.org/10.1002/pc.20130

[56] Saulnier, F. (2013) Influence de traitements physico-chimiques des renforts sur le comportement mécanique des composites à base de co-produits de bois. Université Blaise Pascal-Clermont-Ferrand II, Français. 


\section{Acronyms and Abbreviations}

\section{Symbols}

$\mathrm{MPa}$

UP

BC10\%_T1

BC10\%_T2

BC15\%_T1

BC15\%_T2

BC20\% T2

E ou MOE

$\mathrm{Ta}$

$F_{\text {rup }}$

$\sigma_{\text {rup }}$

$\rho_{c}$

\section{Meanings}

mega-Pascal

Unsatured polyester

Bagasse composite with $10 \%$ fibers $(0.5 \mathrm{~mm}-2.5 \mathrm{~mm})$

Bagasse composite with $10 \%$ fibers $(2.5 \mathrm{~mm}-4 \mathrm{~mm})$

Bagasse composite with $15 \%$ fiber content $(0.5 \mathrm{~mm}-2.5 \mathrm{~mm})$

Bagasse composite with $15 \%$ fiber $(2.5 \mathrm{~mm}-4 \mathrm{~mm})$

Bagasse composite with $20 \%$ fiber $(2.5 \mathrm{~mm}-4 \mathrm{~mm})$

Young's modulus (Mpa)

Water absorption rate (\%)

Breaking force $(\mathrm{N})$

Breaking stree (Mpa)

Density $\left(\mathrm{kg} / \mathrm{m}^{3}\right)$ 